\title{
O CASO DA TERRAPLANAGEM BARBOSA
}

THE CASE OF BARBOSA EARTHWORK

Tiago Farias Dias Universidade de Santa Cruz do Sul - UNISC / RS tiagodiasbr@yahoo.com.br

Derli Luís Angnes Universidade de Santa Cruz do Sul - UNISC / RS derli.angnes@gmail.com

Douglas Wegner Universidade de Santa Cruz do Sul - UNISC / RS douglaswegner@hotmail.com

Submissão: $24 / 04 / 2015$

Aprovação: 30/05/2016 


\title{
RESUMO
}

Este caso para ensino tem como objetivo subsidiar alunos de cursos de graduação e pósgraduação no processo de decisão de viabilidade de investimento a partir de uma análise financeira e econômica de um empreendimento do setor de prestação de serviços. A análise de viabilidade reduz os riscos inerentes ao investimento de capital e proporciona informações relevantes para a tomada de decisão em negócios. Considerando esse aspecto, o caso para ensino propõe a realização de um estudo de viabilidade econômica de um empreendimento em terraplenagem, com base em um caso verídico de consultoria financeira empresarial em uma cidade do interior do Rio Grande do Sul. Ao final do caso, o aluno é instigado a analisar a viabilidade do negócio, por meio das atividades propostas nas notas de ensino.

Palavras-chave: Empreendimento. Finanças. Análise de viabilidade.

\begin{abstract}
This teaching case aims to provide information for undergraduate and MBA students in the decision making process of financial viability based in a financial and economic analysis of a business in the services sector. The viability analysis reduces the risks related to capital investment and provides relevant information for decision making in business. Considering this aspect, the teaching case proposes some pondering by means of an economic viability study of an earthwork business in a city in the countryside of Rio Grande do Sul. At the end of the case the student is urged to analyze the business viability using the proposed activities in the teaching notes.
\end{abstract}

Keywords: Business. Finances. Viability Analysis. 


\section{INTRODUÇÃO}

Segundo o SEBRAE (2014) com base nas estatísticas do GEM (Global Entrepreneurship Monitor) de 2013, estima-se que 40 milhões de brasileiros entre 18 e 64 anos estejam envolvidos em atividades empreendedoras, sendo que $84,6 \%$ dos empreendedores pesquisados responderam que não procuram nenhum órgão de apoio ou ajuda para implementação do seu negócio. Além disso, 52,1\% dos empreendedores pesquisados afirmaram possuir conhecimento, habilidade e experiência para iniciar o seu negócio. Segundo estudos do SEBRAE (2014), as taxas de sobrevivência dos empreendimentos dependem em parte da escolaridade do empreendedor, dos esforços de capacitação e uma legislação favorável.

Diante da ausência de conhecimentos prévios ou de capacitação para análise de investimentos em negócios, a opção por uma consultoria empresarial especializada financeira pode proporcionar ao empreendedor informações relevantes para uma decisão de investimento do seu capital. É neste cenário que se insere o caso do Sr. Antônio Barbosa, um motorista de caminhão que resolve iniciar um empreendimento em terraplanagem e busca auxílio de uma consultoria empresarial para analisar a viabilidade do seu negócio.

\section{O CASO}

Antônio Barbosa trabalhou por muitos anos como motorista de caminhão, sendo funcionário de várias empresas. Após muito tempo conseguiu adquirir um caminhão usado em sociedade com seu irmão mais novo. Atuavam os dois fazendo fretes de rejeitos (pedras que não possuíam tamanhos nem desenho para serem comercializadas) das pedreiras da região. Com o passar do tempo o número de fretes foi diminuindo e eles resolveram parar com o negócio. Venderam o caminhão, dividiram o valor e desfizeram a sociedade. Com a parte que lhe cabia, Antônio iniciou uma loja de ferragem e utensílios para extração de pedras grês, no bairro Morro da Pedra na cidade de Taquara. Sua loja tinha $12 \mathrm{~m}^{2}$, ele deixava parte dos produtos expostos lá e outra parte ele colocava no baú de sua moto e saía para oferecer para os proprietários de pedreiras.

O negócio prosperou e dois anos mais tarde ele já estava trabalhando em um prédio próprio, com área de $100 \mathrm{~m}^{2}$. Foi quando resolveu ampliar o negócio anexando uma oficina à 
loja. Além de vender produtos para os donos de pedreiras ele passou a oferecer manutenção dos equipamentos utilizados para extração. A loja e a oficina vão bem e Antônio pensa em abrir outro negócio, no ramo de terraplenagem. Sua intenção é prestar serviço de escavação e remoção, um negócio totalmente novo para ele. Além do mais ele precisa saber se este negócio é viável, afinal de contas ele quer investir para ampliar o seu patrimônio, e não para ter prejuízo. Por isso ele se questiona: Será que este negócio me dará lucro? Se eu comprar uma máquina e um caminhão conseguirei vender o serviço? Vou conseguir pagar a prestação das máquinas? Será que vale mais a pena investir meu dinheiro em aplicações financeiras?

Como Antônio já havia trabalhado anteriormente com seu irmão, e no momento ele está desempregado, seria uma boa opção chamá-lo para ser sócio deste novo negócio. A ferragem e a oficina já lhe ocupam bastante tempo e certamente seria inviável cuidar dos dois negócios. Contar com alguém de confiança seria indispensável para iniciar um novo negócio. Porém, ele também precisava saber se o empreendimento seria viável ou não. A operação do novo negócio exige a aquisição de dois equipamentos: uma escavadeira hidráulica para 20 toneladas, que gera uma receita média de $\mathrm{R} \$ 200,00$ por hora trabalhada, e um caminhão Truck Traçado $6 \times 4$, que gera uma receita média de $\mathrm{R} \$ 110,00$ por hora trabalhada, de acordo com os valores praticados na região.

\subsection{Consultoria financeira}

Antônio então resolveu contratar um consultor para lhe ajudar na análise de viabilidade do negócio. Por indicação de colegas, o empreendedor chegou ao nome de Arthur Casagrande, um consultor da área financeira com boas referências e grande experiência. Marcaram para se encontrar na empresa de ferragens na semana seguinte. $\mathrm{Na}$ data e hora marcada, Casagrande estava lá. Após se apresentarem, o proprietário da ferragem descreveu sua trajetória para o consultor, no que consistia o seu negócio e por fim detalhou o investimento que queria realizar e a sua preocupação. Casagrande respondeu:

- Antônio, a simples atitude de chamar um consultor para lhe ajudar a verificar a viabilidade do negócio já é um grande passo. Infelizmente muitas pessoas simplesmente investem sem fazer um estudo aprofundado para saber se o negócio é viável ou não, e acabam perdendo dinheiro. Já vi a economia de uma vida inteira sendo perdida por falta de planejamento e análise. Estou aqui para ajudar, mas para isso precisarei de informações mais detalhadas para que possamos verificar a viabilidade do negócio. Você disse que o valor 
praticado no mercado para locação dos equipamentos é de $\mathrm{R} \$ 200,00$ por hora para escavadeira e R \$ 110,00 para o caminhão, certo?

- Sim, algumas empresas cobram R\$190,00, outras R\$210,00, mas na média fica em torno de R \$ 200,00 por hora para escavadeira. Já o serviço do caminhão está na faixa de R\$ 110,00 por hora.

- Ok! Para realizar um estudo mais aprofundado e identificar a viabilidade do negócio teremos que fazer um orçamento de todos os custos envolvidos para cada hora operada destes equipamentos. Você já identificou os custos com combustível e manutenção, por exemplo?

- Segundo meus levantamentos a escavadeira gasta em média 20 litros de combustível por hora operada e o caminhão em torno de 10 litros. Sei também que a máquina precisa ser lubrificada toda a semana.

- Antônio, com certeza existem outros custos, como, por exemplo, a manutenção, depreciação e seguros. Quero que você pesquise o valor da máquina e do caminhão para sabermos o valor do investimento e para que possamos calcular a depreciação e também todos os gastos para operar os equipamentos. Precisaremos estimar despesas de manutenção, pneus, enfim todos os gastos. Você já tem noção do valor do salário dos operadores da máquina e do caminhão? Quero que veja isto também. Você consegue estes dados até a próxima semana para darmos continuidade na análise?

- Sim, pode deixar que terei estes dados à disposição na próxima semana.

\subsection{Obtendo informações para análise do negócio}

Os dois se despediram e, no outro dia, Antônio começou a buscar as informações solicitadas pelo consultor. Pela manhã ele decidiu conversar com operadores para ter ideia dos salários pagos a esses profissionais. $\mathrm{O}$ operador da escavadeira recebe em média salário mensal de $\mathrm{R} \$ 2.000,00$ e o motorista de caminhão em torno de $\mathrm{R} \$ 1.500,00$. Imediatamente após obter estas informações ele telefonou para o contador e pediu um cálculo do salário dos operadores com todos os encargos sociais e trabalhistas. Segundo o contador, levando em consideração os encargos e que no período de férias dos colaboradores (operador e motorista) a empresa precisa contratar trabalhadores temporários, ela precisa reservar 38\% sobre a folha de pagamento. Naquela mesma tarde Antônio visitou uma loja especializada em equipamentos pesados e recebeu os seguintes orçamentos apresentados na Tabela 1. 
A respeito do caminhão, Antônio pesquisou também o consumo de pneus, sendo que o valor de aquisição de cada pneu é de $\mathrm{R} \$ 1.800$, o caminhão utiliza 10 pneus e os mesmos devem ser trocados a cada $20.000 \mathrm{~km}$. A cada hora trabalhada do caminhão ele percorre em média $7 \mathrm{~km}$. Na sexta-feira Antônio já havia conseguido todas as informações e estava ansioso pela chegada do consultor na semana seguinte. Já a escavadeira não possui custo com pneu, pois ela tem esteiras no lugar dos pneus e o desgaste da esteira já está incluído no custo da manutenção.

Tabela 1 - Orçamento da loja

\section{ORÇAMENTO OBRASUL Ltda.}

Válido por 20 dias

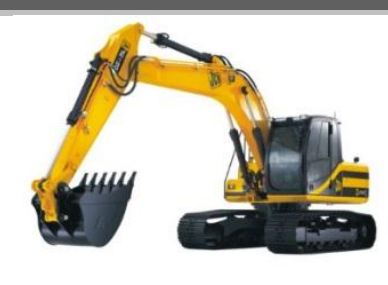

\begin{tabular}{llr}
\hline & \multicolumn{1}{c}{ ORÇAMENTO } \\
Quantidade & \multicolumn{1}{c}{ Descrição } & Valor $(\mathrm{R} \$)$ \\
\hline 1 & Escavadeira hidráulica capacidade de 20 toneladas & $360.000,00$ \\
1 & Caminhão traçado 6x4 basculante & $180.000,00$ \\
\hline
\end{tabular}

\begin{tabular}{|c|c|c|c|c|c|}
\hline \multicolumn{6}{|c|}{ FINANCIAMENTO } \\
\hline Equipamento & Entrada & Valor financiado & $\begin{array}{c}\text { Prazo } \\
\text { Pagamento }\end{array}$ & $\begin{array}{c}\text { Tipo } \\
\text { financiamento }\end{array}$ & Taxa Juros \\
\hline Escavadeira & $20 \%$ & $\mathrm{R} \$ 288.000,00$ & 5 anos & SAC & $9,38 \%$ ao ano \\
\hline Caminhão & $10 \%$ & $\mathrm{R} \$ 162.000,00$ & 5 anos & SAC & $2,55 \%$ ao ano* \\
\hline
\end{tabular}

\begin{tabular}{|c|c|c|}
\hline \multicolumn{3}{|c|}{ MANUTENÇÃO } \\
\hline Equipamento & Manutenção & Custo \\
\hline Escavadeira & Primeiras 1.000 horas & Garantia de fábrica \\
\hline Escavadeira & A cada 500 horas & $\mathrm{R} \$ 20.000,00$ \\
\hline Caminhão & Primeiros $10.000 \mathrm{~km}$ & Garantia de fábrica \\
\hline Caminhão & A cada $5.000 \mathrm{~km}$ & $\mathrm{R} \$ 2.000,00$ \\
\hline
\end{tabular}

Casagrande chegou cedo na quarta-feira e Antônio imediatamente apresentou as propostas e detalhou outras informações que havia coletado: - Veja estas tabelas com informações sobre gastos com combustível, depreciação e seguro (Tabela 2 e 3):

Tabela 2 - Gastos com combustível

\begin{tabular}{lccc}
\hline Equipamento & Consumo diesel (1/h) & Custo por litro (R\$) & Total p/ hora (R\$) \\
\hline Escavadeira & 20 & 2,20 & 44,00 \\
Caminhão & 10 & 2,20 & 22,00 \\
\hline
\end{tabular}

Tabela 3 - Depreciação e seguros

\begin{tabular}{lccccc}
\hline Equipamento & Investimento $(\mathbf{R} \mathbf{)})$ & Vida útil & Depreciação anual $(\mathbf{R} \mathbf{)}$ & Seguro (\%) & Seguro anual $(\mathbf{R} \mathbf{\text { ) }}$ \\
\hline Escavadeira & $360.000,00$ & 5 anos & $72.000,00$ & 3 & $10.800,00$ \\
Caminhão & $180.000,00$ & 5 anos & $36.000,00$ & 5 & $9.000,00$ \\
\hline
\end{tabular}


Casagrande olhou calmamente as propostas, ficou um momento em silêncio apreciando os dados e falou:

- Temos bons dados aqui, sendo possível já realizar alguns cálculos. Vi que você já tem o valor do investimento, o gasto com combustível, manutenção e identificou até possibilidades de financiamentos. Excelente!

Após uma curta pausa, Casagrande continuou: - Já temos boas informações para calcularmos os valores dos custos do negócio, o valor do investimento e sabemos o valor médio cobrado por hora. Agora precisamos estimar o volume de horas ou de dias de operação dos equipamentos. Você tem essas estimativas?

- Isso é relativamente simples: em média são 22 dias úteis. Se trabalharmos 8 horas por dia, é só multiplicar, teremos 176 horas por mês.

- Antônio, isso não é tão simples assim. Você está iniciando um negócio novo, será que vai conseguir operar com toda a capacidade na fase inicial do negócio? Você já tem clientes? Acredito que neste primeiro momento você vai precisar conquistar clientes, divulgar a sua empresa... vai demorar algum tempo para que consiga trabalhar com toda a sua capacidade. Além do mais você conseguirá trabalhar os 22 dias por mês? Nos dias chuvosos será possível trabalhar? Vai prestar serviço para vários clientes? Lembre-se que você precisa deslocar o equipamento de um cliente para o outro e, neste período, ele fica sem trabalhar. O que acha?

- Realmente não tinha me lembrado destes detalhes. Como trabalharemos com movimentação de terras, quando chove é comum que os equipamentos fiquem parados. Às vezes mesmo parando a chuva é necessário esperar o solo secar para dar continuidade no serviço. Quando tem que mudar o equipamento de um cliente para outro também se perde tempo, carregando e descarregando a máquina. Vou ter que pesquisar sobre isso para o próximo encontro.

- Certo, você pode fazer uma média, pode até ser de um ano. Pesquise e veja em média quantos dias úteis são chuvosos durante cada mês. Você precisará ver também se há mercado para locação destes equipamentos. Converse com potenciais clientes, procure ver com eles se estão satisfeitos ou não com as outras empresas disponíveis no mercado. Caso venha a implantar o negócio, descubra quem será o seu principal concorrente. Pode ver isto para a próxima quarta-feira?

- Sim, combinado para a próxima quarta. 
Antônio estava contente com o trabalho do consultor. Ele tinha identificado diversos aspectos que haviam passado despercebidos. Como não tinha pensado nisso? Era óbvio que não seria possível trabalhar todos os dias do mês devido à chuva. Precisava descobrir essa informação, mas não sabia onde. Foi quando lembrou de procurar uma empresa do ramo de construção civil, pois estas também possuem o mesmo problema. No dia seguinte foi recebido pelo proprietário da empresa. Descobriu que o tempo médio mensal de operação varia muito: há meses em que se trabalha 20 dias e outros que se trabalha apenas 10 dias. Na média anual na sua região ele disse que se trabalha 18 dias. Aproveitou e conversou também sobre o serviço de terraplenagem. O empresário comentou que na região havia falta de empresas para realizar o serviço e que, quando precisava contratar uma empresa desse ramo, normalmente a contratada demorava até iniciar o serviço. Antônio questionou também a qualidade dos serviços prestados pelos concorrentes.

No outro dia Antônio foi conversar com outros potenciais clientes para identificar a qualidade e a oferta dos serviços na área. Fez uma pesquisa informal e conseguiu ter informações de como está o mercado e identificar os concorrentes. Faltava identificar ainda o tempo perdido de deslocamento do equipamento de um cliente para outro. Poderia conversar com um possível concorrente, mas será que ele forneceria as informações? Lembrou que poderia contatar informalmente um operador de escavadeira que trabalha para uma empresa na cidade vizinha. Este mencionou que se perde em média uma hora para mudar o equipamento de um lugar para o outro. A respeito da quantidade de deslocamentos mensais, depende do tamanho dos serviços. Há serviços que se trabalha duas semanas, outros apenas um dia, quantos mais serviços de pouca duração forem feitos, mais deslocamentos são realizados. Seria melhor adotar um cálculo pessimista e estimar um dia a menos de trabalho por mês devido aos deslocamentos e parada para realização das manutenções.

Pronto, Antônio tinha todas as informações que Casagrande havia solicitado. Agora era só repassar para o consultor na próxima visita. O consultor chegou na hora marcada e o empreendedor foi logo contando as novidades. Comentou que é possível operar em média 18 dias por mês e que se perde um dia de trabalho para realização dos deslocamentos e realização das manutenções nos equipamentos. Comentou também suas impressões sobre o mercado para o serviço que pretendia iniciar, com bons indícios de que haveria demanda suficiente e mercado a ser atendido. Pelo relato dos potenciais clientes, quando necessitavam do serviço demoravam muito até ser atendidos. Antônio também relatou que no primeiro mês talvez ele conseguisse trabalhar muito pouco, porque precisaria contratar os colaboradores e perderia 
alguns dias formalizando a compra, assinando contratos e fazendo toda a papelada. Enquanto não chegassem os equipamentos não faria sentido contatar potenciais clientes. A partir do segundo mês até o final do primeiro ano ele estimava ocupar $65 \%$ da capacidade produtiva, já do segundo ano em diante esperava trabalhar com $90 \%$ da capacidade.

Ao final da explanação, o consultor comentou:

- Desde a minha primeira visita vi que você já pesquisou bastante sobre as peculiaridades do ramo, conversou com potenciais clientes e fez um pequeno estudo de mercado. Minha consultoria é financeira, entendo um pouco de marketing, mas não sou especialista. Após concluirmos o estudo de viabilidade acho interessante contratar um consultor na área de marketing, para que ele auxilie a melhorar o estudo de mercado e definir melhores estratégias de divulgação da empresa e atração de clientes. Neste primeiro momento vou acrescentar uma despesa de $\mathrm{R} \$ 500,00$ por mês para você investir em marketing. O que você acha?

- Concordo. Se o negócio for viável e eu resolver comprar os equipamentos posso contratar um consultor de marketing e já prever um valor para divulgar a empresa.

- Bom, agora que temos uma previsão de quanto será trabalhado por mês podemos fazer a previsão de receita. Sabemos os custos, então podemos calcular a previsão de custos e despesas. Além disso, sabemos o valor do investimento e das parcelas. Já podemos analisar a viabilidade do negócio, mais ainda falta uma informação.

- Como assim? Acho que já temos todas as informações... O que está faltando?

- Qual a sua principal despesa?

- Acho que é diesel.

- Qual o prazo de pagamento que você recebe para pagar o diesel?

- Recebo dois dias de prazo, ou 30 dias de prazo com acréscimo de 7\% no valor.

- Qual o prazo você vai conceder aos seus clientes?

- A minha política de crédito vai ser similar à das outras empresas, vou conceder no máximo 30 dias de prazo, sendo que o cliente deve pagar 50\% do valor do serviço à vista.

- Qual prazo você recebe dos fornecedores para realizar as manutenções?

- Os fornecedores concedem 30 dias de prazo.

- Bom Antônio, estas informações são importantes para calcular o volume de capital de giro necessário para operar o negócio. O capital de giro é a quantidade de recursos que você vai precisar para honrar seus compromissos até que você receba dos seus clientes. Para cálculo vou considerar ainda que no primeiro mês você não vai trabalhar, porém terá folha de 
pagamentos e demais despesas, bem como suas prestações para pagar. Vou inserir essas informações na minha planilha de cálculo.

O consultor insere as informações na planilha eletrônica e calcula o capital de giro necessário para operar o negócio:

- Antônio, você precisará de R \$37.000,00 de capital de giro.

- Nossa! Não imaginava que iria precisar de mais este valor.

\subsection{Analisando a viabilidade do negócio}

- Bom Antônio, acho que agora já tenho informações suficientes para analisar a viabilidade do negócio. Poderei estimar o montante de receitas, despesas e o valor do investimento. Será possível analisar se o negócio gera recursos suficientes para pagar as prestações. Para analisar a viabilidade preciso saber ainda que taxa de retorno você considera adequada para o seu negócio. Existem métodos para calcular esta taxa em empresas maiores, por meio dos resultados da empresa e do nível de risco do setor. No entanto, a sua empresa é nova, então podemos arbitrar uma taxa. Ela precisa ser uma taxa que remunere os riscos que você está correndo. Que taxa acredita ser a mais adequada?

- Bom, se investir em uma caderneta de poupança ou um CDB vou receber em média 6 a $7 \%$ ao ano. Acredito que uma boa taxa seja de $12 \%$, o que acha?

- Olha, no cenário atual penso ser adequada uma taxa de $12 \%$ para remuneração do capital próprio. Conforme já mencionei tenho todos os dados necessários, agora quem pede um tempo sou eu. A tarefa de casa agora é do consultor, dentro de uma semana volto e trago todo o estudo de viabilidade do negócio. Vou realizar duas análises: a primeira, se você optar por investir com recursos próprios, e a segunda, se você optar por financiar os equipamentos.

Ok? Até a próxima semana.

- Até a próxima semana.

Casagrande precisava dar uma resposta para Antônio, dizendo se o negócio é viável ou não em cada uma das duas alternativas. No caminho para casa ficou pensando quantas horas esta empresa vai trabalhar por mês? Qual seu faturamento mensal? Qual seu faturamento anual? Quanto vai gastar de manutenção? Quanto vai gastar de combustível? Qual o custo por hora trabalhada? Qual o valor das suas despesas operacionais? Quanto será a parcela dos equipamentos? O negócio é viável? 
ANEXO

\section{NOTAS DE ENSINO: ORIENTAÇÕES PARA PROFESSORES}

\section{1 Área de conhecimento e público a quem se destina o caso}

O caso de ensino foi elaborado para ser utilizado em cursos de graduação e pósgraduação, em conteúdos de disciplinas relacionadas a administração de serviços, operações e finanças. Os autores testaram previamente o caso em disciplinas de finanças em cursos de graduação. É sugerido ao docente que antes de aplicar o caso para ensino sejam desenvolvidos em aula conceitos e técnicas de análise de viabilidade, necessários para a solução do caso. Alguns livros-texto são sugeridos nas referências e bibliografias do caso e podem ser indicados aos alunos para complementar a solução do problema.

\subsection{Objetivos pedagógicos}

O caso de ensino proposto tem como objetivo principal a análise de viabilidade financeira e econômica de um empreendimento em terraplenagem. Para tanto, os objetivos específicos são: (1) Compreender a importância dos gastos envolvidos em um empreendimento de prestação de serviços em terraplenagem e realizar o processo orçamentário; (2) Analisar a partir de cálculos financeiros a viabilidade do negócio; (3) Tomar a melhor decisão de investimento do capital.

\subsection{Obtenção dos dados}

Os dados informados foram obtidos por meio de um caso verídico, envolvendo uma consultoria financeira para averiguar a viabilidade de um negócio em terraplenagem em uma cidade do Rio Grande do Sul. Os nomes dos personagens utilizados no caso são fictícios. Parte da história apresenta elementos reais, adaptados didaticamente para construção do caso para ensino em sala de aula. 


\subsection{Questões para a discussão do caso}

Para discussão do caso em sala de aula, o professor poderá utilizar as questões sugeridas a seguir:

1) Monte equipes de dois a seis alunos. Os alunos devem se colocar na função do consultor e realizar o estudo de viabilidade do negócio, apresentando detalhadamente todas as etapas do processo orçamentário, tendo como sugestão as etapas a seguir:

a) Identifique o número de horas trabalhadas mensais e anuais e faça uma planilha de faturamento da empresa;

b) Identifique o custo por hora trabalhada (diesel) e faça uma planilha de horas e quilômetros acumulados para calcular os gastos com manutenção e pneu;

c) Identifique todas as despesas operacionais (salários, seguros, depreciações, despesas com marketing) e faça uma planilha de gastos anuais;

d) Faça uma planilha de financiamento dos equipamentos separando o valor da amortização e o valor dos juros;

e) Faça o fluxo de caixa para o período de cinco anos e analise a viabilidade do negócio nas duas alternativas: com recursos próprios e financiando os equipamentos. Considere uma alíquota de imposto de renda de $30 \%$.

f) Utilizando os critérios de análise de investimento (VPL, Payback descontado e TIR) o negócio é viável e deve ser levado adiante? Por quê?

g) $\mathrm{O}$ que aconteceria com o empreendimento se a taxa mínima de atratividade fosse reduzida?

h) Que conselhos você daria para Antônio caso ele iniciasse o negócio?

\subsection{Estratégias de ensino}

Para um melhor aproveitamento da aplicação do caso para ensino em sala de aula, sugere-se ao professor que siga o roteiro apresentado a seguir:

a) Abordagem teórica prévia dos principais conceitos necessários para resolução do caso para ensino; 
b) Leitura do caso para ensino em sala de aula;

c) Formação de grupos de alunos para discussão e resolução das questões propostas, preferencialmente com auxílio de planilha eletrônica;

d) Apresentação dos resultados de cada grupo. Ao final, os resultados poderão ser corrigidos pelo professor ou pelos próprios alunos, tendo como referência as respostas apresentadas neste caso.

\subsection{Conceitos teóricos}

\subsubsection{Análise de Investimentos}

Para Galesne, Fensterseifer e Lamb (1999), investimento consiste em comprometer capital com a expectativa de manter ou melhorar sua situação econômica. Geralmente os recursos (capital) são escassos, mas existe uma diversidade de opções para aplicá-los, cabendo ao tomador de decisão investi-los naqueles que trarão maior riqueza para organização de acordo com a sua situação e os riscos que está disposta a correr.

Para Brigham, Gapenski e Ehrhardt (2001), a análise de investimentos consiste em avaliar projetos de investimento auxiliando na tomada de decisão no orçamento de capital da organização. Alguns métodos são úteis para analisar investimentos tais como, Payback Descontado, Valor Presente Líquido e Taxa Interna de Retorno que serão abordados no presente trabalho.

\subsubsection{Método do Valor Presente Líquido}

O método do Valor Presente Líquido (VPL) é o mais utilizado e conhecido pelas organizações para comparar os investimentos (SOUZA, 2009). Para Assaf Neto (2009, p.153) "O método do valor presente líquido [...] é obtido pela diferença entre o valor presente dos benefícios (ou pagamentos) previstos de caixa e o valor presente do fluxo de caixa inicial (valor do investimento)". Porém, tanto o valor do investimento quanto dos benefícios deve ser descontado a uma taxa estipulada pela organização. A fórmula para cálculo do VPL é a seguinte: 


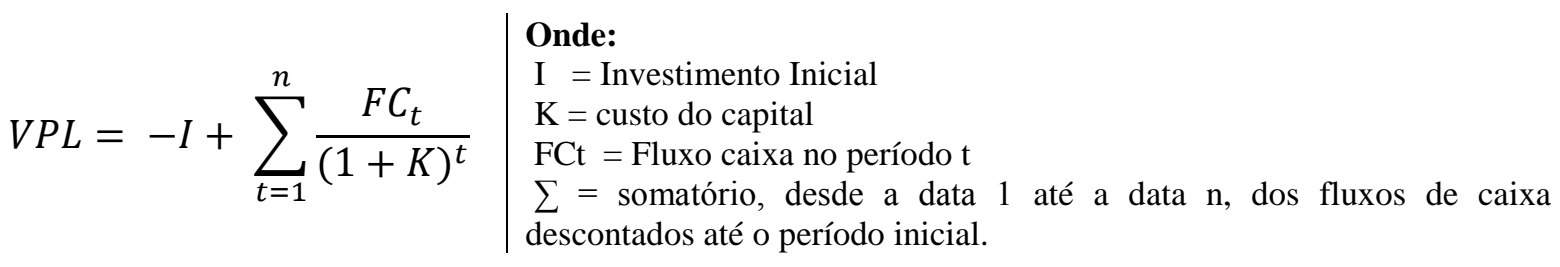

O valor do VPL representa quanto a organização ganha em valores monetários de hoje se aplicar os seus recursos no projeto, sendo o ganho adicional a remuneração recebida pela aplicação do dinheiro ao custo do capital. Quanto maior o VPL, maior o retorno monetário para a empresa.

De acordo com Lapponi (2000), se o resultado do VPL for maior que zero, o projeto de investimento é viável, porém, se o resultado do VPL for menor que zero, o projeto de investimento não deverá ser aceito, e se ele obtiver o resultado igual a zero será indiferente aceitar o projeto.

\subsubsection{Taxa Interna de Retorno}

A Taxa Interna de Retorno (TIR) é a taxa que ao descontar todos os ingressos e desembolsos de um projeto de investimento à data zero anulam o VPL, ou seja, "[...] é a taxa que torna o Valor Presente Líquido (VPL) de um fluxo de caixa igual a zero". (SOUZA, 2009, p.81), segundo a fórmula na sequência:

$V P L=-I+\sum_{t=1}^{n} \frac{F C_{t}}{(1+i)^{t}}=0 \quad \begin{aligned} & \text { Onde: } \\ & \text { i é a TIR do projeto, a taxa que torna o VPL zero. } \\ & \mathrm{I}=\text { Investimento Inicial } \\ & \mathrm{FCt}=\text { Fluxo caixa no período } \mathrm{t} \\ & \begin{array}{l}\sum=\text { somatório, desde a data } 1 \text { até a data } \mathrm{n} \text {, dos fluxos de caixa } \\ \text { descontados até o período inicial }\end{array}\end{aligned}$

O cálculo da TIR é considerado trabalhoso por tratar-se de uma função polinomial de grandeza maior do que dois, quando calculada manualmente. O cálculo é realizado por tentativa e erro. A utilização de planilha eletrônica ou calculadora financeira facilita o cálculo.

Segundo Gitman (2004), a TIR é a técnica de orçamento de capital sofisticada mais utilizada. E para o projeto de investimento ser aceito a TIR do investimento tem que ser sempre maior que o custo do capital.

A TIR é a maior taxa que um investimento pode oferecer de retorno. Para Kassai et al (2000, p.66) "é considerado economicamente atraente todo o investimento que apresente TIR maior ou igual a TMA". 


\subsubsection{Método do Payback Descontado}

Para Samanez (2009), o método do payback descontado consiste em identificar quanto tempo os fluxos de caixa gerados levariam para recuperar o valor investido, levando em consideração o custo do capital, ou a taxa mínima de atratividade estipulada pela organização.

Para Souza (2009, p.90) "O risco do projeto aumenta à medida que o payback se aproxima do final do horizonte de planejamento.”. Isto porque aumenta a possibilidade de variações no mercado ou na economia, por exemplo. Sendo assim, os fluxos de caixa de tempos elevados possuem mais riscos de não se realizarem, ou se realizarem com distorções.

Lapponi (2000) complementa que a organização deve definir o tempo máximo tolerado para recuperação do capital investido; se o payback do projeto de investimento for menor que este tempo estipulado o projeto deve ser aceito, caso contrário, deve ser descartado.

\subsection{Análise e solução do caso}

\subsubsection{Resolução da questão (a):}

Considerando que a empresa trabalha 17 dias por mês e uma carga horária de 8 horas por dia, conclui-se que a capacidade máxima de trabalho da empresa é de 136 horas por mês. Levando em consideração a expectativa de trabalho da empresa a previsão de horas trabalhadas mensais está expressa na tabela 4:

Tabela 4 - Expectativa de número de horas trabalhadas:

\begin{tabular}{lrrr}
\hline Estimativa de trabalho da capacidade & Percentual & Horas Caminhão & Horas Máquinas \\
\hline Ano $1:$ do $2^{\circ}$ ao $12^{\circ}$ mês & $65 \%$ & 88,4 & 88,4 \\
Ano 2: do $1^{\circ}$ ao $12^{\circ}$ mês & $90 \%$ & 122,4 & 122,4 \\
Ano 3: do $1^{\circ}$ ao $12^{\circ}$ mês & $90 \%$ & 122,4 & 122,4 \\
Ano 4: do $1^{\circ}$ ao $12^{\circ}$ mês & $90 \%$ & 122,4 & 122,4 \\
Ano 5: do $1^{\circ}$ ao $12^{\circ}$ mês & $90 \%$ & 122,4 & 122,4 \\
\hline
\end{tabular}

Com base na tabela 4 e nos preços propostos pela empresa ( $\mathrm{R} \$ 200,00$ por hora de trabalho da escavadeira e R\$ 110 por hora de trabalho do caminhão) elaborou-se a seguinte previsão de faturamento da empresa (tabela 5). 
Tabela 5 - Previsão de Faturamento

\begin{tabular}{|c|c|c|c|c|c|c|c|c|c|c|}
\hline \multirow{2}{*}{ Mês } & \multirow{2}{*}{\multicolumn{2}{|c|}{$\begin{array}{c}\text { Ano } 1(\mathbf{R} \$) \\
\text { Escavadeira Caminhão }\end{array}$}} & \multirow{2}{*}{\multicolumn{2}{|c|}{$\begin{array}{c}\text { Ano } 2 \text { (R\$) } \\
\text { Escavadeira Caminhão }\end{array}$}} & \multirow{2}{*}{\multicolumn{2}{|c|}{$\begin{array}{c}\text { Ano } 3(\mathbf{R} \$) \\
\text { Escavadeira Caminhão }\end{array}$}} & \multirow{2}{*}{\multicolumn{2}{|c|}{$\begin{array}{c}\text { Ano } 4(\mathrm{R} \$) \\
\text { Escavadeira Caminhão }\end{array}$}} & \multirow{2}{*}{\multicolumn{2}{|c|}{$\begin{array}{c}\text { Ano 5 (R\$) } \\
\text { Escavadeira Caminhão }\end{array}$}} \\
\hline & & & & & & & & & & \\
\hline Mês 1 & & & $24.480,00$ & $13.464,00$ & $24.480,00$ & $13.464,00$ & $24.480,00$ & $13.464,00$ & $24.480,00$ & $13.464,00$ \\
\hline Mês 2 & $17.680,00$ & $9.724,00$ & $24.480,00$ & $13.464,00$ & $24.480,00$ & $13.464,00$ & $24.480,00$ & $13.464,00$ & $24.480,00$ & $13.464,00$ \\
\hline Mês 3 & $17.680,00$ & $9.724,00$ & $24.480,00$ & $13.464,00$ & $24.480,00$ & $13.464,00$ & $24.480,00$ & $13.464,00$ & $24.480,00$ & $13.464,00$ \\
\hline Mês 4 & $17.680,00$ & $9.724,00$ & $24.480,00$ & $13.464,00$ & $24.480,00$ & $13.464,00$ & $24.480,00$ & $13.464,00$ & $24.480,00$ & $13.464,00$ \\
\hline Mês 5 & $17.680,00$ & $9.724,00$ & $24.480,00$ & $13.464,00$ & $24.480,00$ & $13.464,00$ & $24.480,00$ & $13.464,00$ & $24.480,00$ & $13.464,00$ \\
\hline Mês 6 & $17.680,00$ & $9.724,00$ & $24.480,00$ & $13.464,00$ & $24.480,00$ & $13.464,00$ & $24.480,00$ & $13.464,00$ & $24.480,00$ & $13.464,00$ \\
\hline Mês 7 & $17.680,00$ & $9.724,00$ & $24.480,00$ & $13.464,00$ & $24.480,00$ & $13.464,00$ & $24.480,00$ & $13.464,00$ & $24.480,00$ & $13.464,00$ \\
\hline Mês 8 & $17.680,00$ & $9.724,00$ & $24.480,00$ & $13.464,00$ & $24.480,00$ & $13.464,00$ & $24.480,00$ & $13.464,00$ & $24.480,00$ & $13.464,00$ \\
\hline Mês 9 & $17.680,00$ & $9.724,00$ & $24.480,00$ & $13.464,00$ & $24.480,00$ & $13.464,00$ & $24.480,00$ & $13.464,00$ & $24.480,00$ & $13.464,00$ \\
\hline Mês 10 & $17.680,00$ & $9.724,00$ & $24.480,00$ & $13.464,00$ & $24.480,00$ & $13.464,00$ & $24.480,00$ & $13.464,00$ & $24.480,00$ & $13.464,00$ \\
\hline Mês 11 & $17.680,00$ & $9.724,00$ & $24.480,00$ & $13.464,00$ & $24.480,00$ & $13.464,00$ & $24.480,00$ & $13.464,00$ & $24.480,00$ & $13.464,00$ \\
\hline Mês 12 & $17.680,00$ & $9.724,00$ & $24.480,00$ & $13.464,00$ & $24.480,00$ & $13.464,00$ & $24.480,00$ & $13.464,00$ & $24.480,00$ & $13.464,00$ \\
\hline Total & $94.480,00$ & $106.964,00$ & $293.760,00$ & $161.568,00$ & $293.760,00$ & $161.568,00$ & 293.76 & $61.568,00$ & $293.760,00$ & $161.568,00$ \\
\hline Anual & 301.44 & 4,00 & 455.32 & 8,00 & 455.32 & 8,00 & 455.32 & 28,00 & 455.32 & 8,00 \\
\hline
\end{tabular}

\subsubsection{Resolução da questão (b):}

Conforme pode ser observado na tabela 1, o equipamento escavadeira hidráulica possui garantia de fábrica de 1.000 horas. Logo, no primeiro mês do ano 2 o equipamento realiza a primeira manutenção. Depois as manutenções ocorrem a cada 500 horas. A primeira manutenção do caminhão é com $10.000 \mathrm{~km}$ o que ocorre no mês 4 do ano 2, as próximas acontecem a cada $5.000 \mathrm{~km}$. Os pneus são trocados a cada $20.000 \mathrm{~km}$. Estão em destaque na tabela as manutenções da escavadeira e do caminhão e as trocas de pneu.

Tabela 6 - Horas de trabalho acumuladas

\begin{tabular}{|c|c|c|c|c|c|c|c|c|c|c|}
\hline \multirow[b]{2}{*}{ Mês } & \multicolumn{2}{|c|}{ Ano 1} & \multicolumn{2}{|c|}{ Ano 2} & \multicolumn{2}{|c|}{ Ano 3} & \multicolumn{2}{|c|}{ Ano 4} & \multicolumn{2}{|c|}{ Ano 5} \\
\hline & $\begin{array}{l}\text { Horas } \\
\text { Acum. }\end{array}$ & $\begin{array}{c}\text { Km } \\
\text { Acumulada }\end{array}$ & $\begin{array}{l}\text { Horas } \\
\text { Acum. }\end{array}$ & $\begin{array}{c}\text { Km } \\
\text { Acumulada }\end{array}$ & $\begin{array}{l}\text { Horas } \\
\text { Acum. }\end{array}$ & $\begin{array}{c}\text { Km } \\
\text { Acumulada }\end{array}$ & $\begin{array}{l}\text { Horas } \\
\text { Acum. }\end{array}$ & $\begin{array}{c}\text { Km } \\
\text { Acumulada }\end{array}$ & $\begin{array}{l}\text { Horas } \\
\text { Acum. }\end{array}$ & $\begin{array}{c}\text { Km } \\
\text { Acumulada }\end{array}$ \\
\hline Mês 1 & 0 & 0,0 & $1.094,8$ & $7.663,6$ & $2.563,6$ & $17.945,2$ & $4.032,4$ & $28.226,8$ & $5.501,2$ & $38.508,4$ \\
\hline Mês 2 & 88,4 & 618,8 & $1.217,2$ & $8.520,4$ & $2.686,0$ & $18.802,0$ & $4.154,8$ & $29.083,6$ & $5.623,6$ & $39.365,2$ \\
\hline Mês 3 & 176,8 & $1.237,6$ & $1.339,6$ & $9.377,2$ & $2.808,4$ & $19.658,8$ & $4.277,2$ & $29.940,4$ & $5.746,0$ & $40.222,0$ \\
\hline Mês 4 & 265,2 & $1.856,4$ & $1.462,0$ & $10.234,0$ & $2.930,8$ & $20.515,6$ & $4.399,6$ & $30.797,2$ & $5.868,4$ & $41.078,8$ \\
\hline Mês 5 & 353,6 & $2.475,2$ & $1.584,4$ & $11.090,8$ & $3.053,2$ & $21.372,4$ & $4.522,0$ & $31.654,0$ & $5.990,8$ & $41.935,6$ \\
\hline Mês 6 & 442 & $3.094,0$ & $1.706,8$ & $11.947,6$ & $3.175,6$ & $22.229,2$ & $4.644,4$ & $32.510,8$ & $6.113,2$ & $42.792,4$ \\
\hline Mês 7 & 530,4 & $3.712,8$ & $1.829,2$ & $12.804,4$ & $3.298,0$ & $23.086,0$ & $4.766,8$ & $33.367,6$ & $6.235,6$ & $43.649,2$ \\
\hline Mês 8 & 618,8 & $4.331,6$ & $1.951,6$ & $13.661,2$ & $3.420,4$ & $23.942,8$ & $4.889,2$ & $34.224,4$ & $6.358,0$ & $44.506,0$ \\
\hline Mês 9 & 707,2 & $4.950,4$ & $2.074,0$ & $14.518,0$ & $3.542,8$ & $24.799,6$ & $5.011,6$ & $35.081,2$ & $6.480,4$ & $45.362,8$ \\
\hline Mês 10 & 795,6 & $5.569,2$ & $2.196,4$ & $15.374,8$ & $3.665,2$ & $25.656,4$ & $5.134,0$ & $35.938,0$ & $6.602,8$ & $46.219,6$ \\
\hline Mês 11 & 884 & $6.188,0$ & $2.318,8$ & $16.231,6$ & $3.787,6$ & $26.513,2$ & $5.256,4$ & $36.794,8$ & $6.725,2$ & $47.076,4$ \\
\hline Mês 12 & 972,4 & $6.806,8$ & $2.441,2$ & $17.088,4$ & $3.910,0$ & $27.370,0$ & $5.378,8$ & $37.651,6$ & $6.847,6$ & $47.933,2$ \\
\hline
\end{tabular}

Conforme pode ser observado na tabela 6 , consta o número de manutenções por equipamento em cada ano e o gasto total com manutenção da escavadeira e do caminhão. Descontou-se do número de manutenções do ano 2 , uma manutenção de cada equipamento porque a primeira manutenção é garantia de fábrica, não tendo custos para a empresa. Consta também o gasto com pneu, levando-se em consideração que o caminhão utiliza 10 pneus e que o custo de cada pneu é de $\mathrm{R} \$ 1.800,00$, quando a empresa realiza a troca ela desembolsa $\mathrm{R} \$ 18.000,00$. 
Tabela 7 - Gastos com manutenção e pneu

\begin{tabular}{|c|c|c|c|c|c|c|c|c|c|c|}
\hline \multirow{2}{*}{ Ano } & \multicolumn{3}{|c|}{ Manutencão Escavadeira } & \multicolumn{3}{|c|}{ Manutenção Caminhão } & \multicolumn{3}{|c|}{ Troca Pneu } & \multirow{2}{*}{$\begin{array}{c}\text { Total Geral } \\
(\mathrm{R} \$)\end{array}$} \\
\hline & Qtd & Valor $(\mathbf{R} \$)$ & Total (R\$) & Qtd & Valor $(\mathbf{R} \$)$ & Total (R\$) & Qtd & Valor $(\mathbf{R} \$)$ & Total (R\$) & \\
\hline Ano 1 & 0 & $20.000,00$ & $\mathrm{R} \$ 0,00$ & 0 & $2.000,00$ & 0,00 & 0 & $18.000,00$ & 0,00 & 0,00 \\
\hline Ano 2 & 2 & $20.000,00$ & $40.000,00$ & 1 & $2.000,00$ & $2.000,00$ & 0 & $18.000,00$ & 0,00 & $42.000,00$ \\
\hline Ano 3 & 3 & $20.000,00$ & $60.000,00$ & 2 & $2.000,00$ & $4.000,00$ & 1 & $18.000,00$ & $18.000,00$ & $82.000,00$ \\
\hline Ano 4 & 3 & $20.000,00$ & $60.000,00$ & 2 & $2.000,00$ & $4.000,00$ & 0 & $18.000,00$ & 0,00 & $64.000,00$ \\
\hline Ano 5 & 3 & $20.000,00$ & $60.000,00$ & 2 & $2.000,00$ & $4.000,00$ & 1 & $18.000,00$ & $18.000,00$ & $82.000,00$ \\
\hline
\end{tabular}

Tendo como referência as tabelas 2 e 4 elaborou-se a tabela 8 , referente ao gasto com combustível:

Tabela 8 - Gastos com combustível

\begin{tabular}{|c|c|c|c|c|c|c|c|c|c|c|}
\hline \multirow{2}{*}{ Mês } & \multicolumn{2}{|c|}{ Ano $1(\mathbf{R} \$)$} & \multicolumn{2}{|c|}{ Ano $2(\mathrm{R} \$)$} & \multicolumn{2}{|c|}{ Ano 3 (R\$) } & \multicolumn{2}{|c|}{ Ano $4($ R\$) } & \multicolumn{2}{|c|}{ Ano $5(\mathrm{R} \$)$} \\
\hline & Escav & aminhão & Escav & $\operatorname{aminhã~}$ & Escavade & Caminhâ & Escavadeira & Caminhão & Escavadeir & Cam \\
\hline Mês 1 & & & $5.385,60$ & $2.692,80$ & $5.385,60$ & $2.692,80$ & $5.385,60$ & $2.692,80$ & $5.385,60$ & $2.692,80$ \\
\hline Mês 2 & $3.889,60$ & $1.944,80$ & $5.385,60$ & $2.692,80$ & $5.385,60$ & $2.692,80$ & $5.385,60$ & $2.692,80$ & $5.385,60$ & $2.692,80$ \\
\hline Mês 3 & $3.889,60$ & $1.944,80$ & $5.385,60$ & $2.692,80$ & $5.385,60$ & $2.692,80$ & $5.385,60$ & $2.692,80$ & $5.385,60$ & $2.692,80$ \\
\hline Mês 4 & $3.889,60$ & $1.944,80$ & $5.385,60$ & $2.692,80$ & $5.385,60$ & $2.692,80$ & $5.385,60$ & $2.692,80$ & $5.385,60$ & $2.692,80$ \\
\hline Mês 5 & $3.889,60$ & $1.944,80$ & $5.385,60$ & $2.692,80$ & $5.385,60$ & $2.692,80$ & $5.385,60$ & $2.692,80$ & $5.385,60$ & $2.692,80$ \\
\hline Mês 6 & $3.889,60$ & $1.944,80$ & $5.385,60$ & $2.692,80$ & $5.385,60$ & $2.692,80$ & $5.385,60$ & $2.692,80$ & $5.385,60$ & $2.692,80$ \\
\hline Mês 7 & $3.889,60$ & $1.944,80$ & $5.385,60$ & $2.692,80$ & $5.385,60$ & $2.692,80$ & $5.385,60$ & $2.692,80$ & $5.385,60$ & $2.692,80$ \\
\hline Mês 8 & $3.889,60$ & $1.944,80$ & $5.385,60$ & $2.692,80$ & $5.385,60$ & $2.692,80$ & $5.385,60$ & $2.692,80$ & $5.385,60$ & $2.692,80$ \\
\hline Mês 9 & $3.889,60$ & $1.944,80$ & $5.385,60$ & $2.692,80$ & $5.385,60$ & $2.692,80$ & $5.385,60$ & $2.692,80$ & $5.385,60$ & $2.692,80$ \\
\hline Mês 10 & $3.889,60$ & $1.944,80$ & $5.385,60$ & $2.692,80$ & $5.385,60$ & $2.692,80$ & $5.385,60$ & $2.692,80$ & $5.385,60$ & $2.692,80$ \\
\hline Mês 11 & $3.889,60$ & $1.944,80$ & $5.385,60$ & $2.692,80$ & $5.385,60$ & $2.692,80$ & $5.385,60$ & $2.692,80$ & $5.385,60$ & $2.692,80$ \\
\hline Mês 12 & $3.889,60$ & $1.944,80$ & $5.385,60$ & $2.692,80$ & $5.385,60$ & $2.692,80$ & $5.385,60$ & $2.692,80$ & $5.385,60$ & $2.692,80$ \\
\hline Total & $42.785,60$ & $21.392,80$ & 64.627,20 & $32.313,60$ & 64.627,20 & $32.313,60$ & 64.627,20 & $32.313,60$ & $4.627,20$ & $32.313,60$ \\
\hline Total geral & 64.178 & 8,40 & 96.940 & 0,80 & 96.940 & 0,80 & 96.940 & 0,80 & 96.940 & $\mathbf{0 , 8 0}$ \\
\hline
\end{tabular}

\subsubsection{Resolução da questão (c):}

Considerando que a empresa possui uma despesa mensal de $\mathrm{R} \$$ 500,00 em marketing, considera-se um custo anual de $\mathrm{R} \$ 6.000,00$. Nas despesas de salário já estão consideradas a provisão para encargos sociais e contratação de profissionais temporários no período de férias do operador e motorista. As demais despesas operacionais da empresa estão expressas na tabela 9:

Tabela 9 - Despesas operacionais anuais

\begin{tabular}{lr}
\hline \multicolumn{1}{c}{ Despesas } & Valores (R\$) \\
\hline Salário e encargos do motorista & $24.840,00$ \\
Salário e encargos do operador de escavadeira & $33.120,00$ \\
Seguro da escavadeira & $10.800,00$ \\
Seguro do caminhão & $9.000,00$ \\
Depreciação da escavadeira & $72.000,00$ \\
Depreciação do caminhão & $36.000,00$ \\
Despesas de marketing & $6.000,00$ \\
\hline Total & $191.760,00$ \\
\hline
\end{tabular}

3.7.4 Resolução da questão (d):

A tabela 10 apresenta o cálculo do financiamento da escavadeira pelo Sistema de Amortização Constante (SAC), considerando uma taxa de juros de 9,38\% ao ano. 
Tabela 10 - Tabela de financiamento da escavadeira

\begin{tabular}{|c|c|c|c|c|c|}
\hline Ano & Empréstimo & Amortização & Saldo & Juros & Parcela \\
\hline 0 & $\mathrm{R} \$ 288.000,00$ & & $\mathrm{R} \$ 288.000,00$ & & \\
\hline 1 & & $R \$ 57.600,00$ & $\mathrm{R} \$ 230.400,00$ & $\mathrm{R} \$ 27.014,40$ & $\mathrm{R} \$ 84.614,40$ \\
\hline 2 & & $\mathrm{R} \$ 57.600,00$ & $\mathrm{R} \$ 172.800,00$ & $\mathrm{R} \$ 21.611,52$ & $\mathrm{R} \$ 79.211,52$ \\
\hline 3 & & $\mathrm{R} \$ 57.600,00$ & $\mathrm{R} \$ 115.200,00$ & $\mathrm{R} \$ 16.208,64$ & $\mathrm{R} \$ 73.808,64$ \\
\hline 4 & & $\mathrm{R} \$ 57.600,00$ & $\mathrm{R} \$ 57.600,00$ & $\mathrm{R} \$ 10.805,76$ & $\mathrm{R} \$ 68.405,76$ \\
\hline 5 & & $\mathrm{R} \$ 57.600,00$ & $\mathrm{R} \$ 0,00$ & $\mathrm{R} \$ 5.402,88$ & $\mathrm{R} \$ 63.002,88$ \\
\hline
\end{tabular}

A tabela 11 apresenta o cálculo do financiamento do caminhão pelo SAC, considerando uma taxa de juros de $2,55 \%$ ao ano.

Tabela 11 - Tabela de financiamento do caminhão

\begin{tabular}{|c|c|c|c|c|c|}
\hline Ano & Empréstimo & Amortização & Saldo & Juros & Parcela \\
\hline 0 & $\mathrm{R} \$ 162.000,00$ & & $\mathrm{R} \$ 162.000,00$ & & \\
\hline 1 & & $\mathrm{R} \$ 32.400,00$ & $\mathrm{R} \$ 129.600,00$ & $\mathrm{R} \$ 4.131,00$ & $\mathrm{R} \$ 36.531,00$ \\
\hline 2 & & $\mathrm{R} \$ 32.400,00$ & $\mathrm{R} \$ 97.200,00$ & $\mathrm{R} \$ 3.304,80$ & $\mathrm{R} \$ 35.704,80$ \\
\hline 3 & & $\mathrm{R} \$ 32.400,00$ & $\mathrm{R} \$ 64.800,00$ & $\mathrm{R} \$ 2.478,60$ & $\mathrm{R} \$ 34.878,60$ \\
\hline 4 & & $\mathrm{R} \$ 32.400,00$ & $\mathrm{R} \$ 32.400,00$ & $\mathrm{R} \$ 1.652,40$ & $\mathrm{R} \$ 34.052,40$ \\
\hline 5 & & $\mathrm{R} \$ 32.400,00$ & $\mathrm{R} \$ 0,00$ & $\mathrm{R} \$ 826,20$ & $\mathrm{R} \$ 33.226,20$ \\
\hline
\end{tabular}

3.7.5 Resolução da questão (e):

A seguir fluxo de caixa da empresa para período de 5 anos:

Tabela 12 - Fluxo de caixa do projeto de investimento

\begin{tabular}{|c|c|c|c|c|c|c|c|}
\hline Contas & Tabela/Origem & Ano 0 (R\$) & Ano 1 (R\$) & Ano 2 (R\$) & Ano 3 (R\$) & Ano 4 (R\$) & Ano 5 (R\$) \\
\hline (+)Receita Escavadeira & 5 & & $194.480,00$ & $293.760,00$ & $293.760,00$ & $293.760,00$ & $293.760,00$ \\
\hline (+)Receita Caminhão & 5 & & $106.964,00$ & $161.568,00$ & $161.568,00$ & $161.568,00$ & $161.568,00$ \\
\hline (=)Receita Total & 5 & & $301.444,00$ & $455.328,00$ & $455.328,00$ & $455.328,00$ & $455.328,00$ \\
\hline (-)Gastos com combustível & 8 & & $-64.178,40$ & $-96.940,80$ & $-96.940,80$ & $-96.940,80$ & $-96.940,80$ \\
\hline (-)Gastos com Manut. E pneu & 7 & & 0,00 & $-42.000,00$ & $-82.000,00$ & $-64.000,00$ & $-82.000,00$ \\
\hline (=)Margem Bruta & & & $237.265,60$ & $316.387,20$ & $276.387,20$ & $294.387,20$ & $276.387,20$ \\
\hline (-)Despesas Operacionais & 9 & & $-191.760,00$ & $-191.760,00$ & $-191.760,00$ & $-191.760,00$ & $-191.760,00$ \\
\hline (=)Lajir & & & $45.505,60$ & $124.627,20$ & $84.627,20$ & $102.627,20$ & $84.627,20$ \\
\hline$(-) I R$ & & & $-13.651,68$ & $-37.388,16$ & $-25.388,16$ & $-30.788,16$ & $-25.388,16$ \\
\hline (=)Lucro Líquido & & & $31.853,92$ & $87.239,04$ & $59.239,04$ & $71.839,04$ & $59.239,04$ \\
\hline (+)Depreciação & 9 & & $108.000,00$ & $108.000,00$ & $108.000,00$ & $108.000,00$ & $108.000,00$ \\
\hline (=)Fluxo Operacional & & & $139.853,92$ & $195.239,04$ & $167.239,04$ & $179.839,04$ & $167.239,04$ \\
\hline (-)Investimento & 1 & $-540.000,00$ & & & & & \\
\hline (-)Capital de Giro & & $-37.000,00$ & & & & & \\
\hline (=)Fluxo Econômico & & $-577.000,00$ & $139.853,92$ & $195.239,04$ & $167.239,04$ & $179.839,04$ & $167.239,0$ \\
\hline (+)Financiamento & 10 e 11 & $450.000,00$ & & & & & \\
\hline (-)Amortização & 10 e 11 & & $-90.000,00$ & $-90.000,00$ & $-90.000,00$ & $-90.000,00$ & $-90.000,00$ \\
\hline$(-)$ Juros & 10 e 11 & & $-31.145,40$ & $-24.916,32$ & $-18.687,24$ & $-12.458,16$ & $-6.229,08$ \\
\hline (+)Benefício Fiscal & & & $9.343,62$ & $7.474,90$ & $5.606,17$ & $3.737,45$ & $1.868,72$ \\
\hline (=)Fluxo Financiamento & & $450.000,00$ & $-111.801,78$ & $-107.441,42$ & $-103.081,07$ & $-98.720,71$ & $-94.360,36$ \\
\hline (=)Fluxo Econômico Financeiro & & $-127.000,00$ & $28.052,14$ & $87.797,62$ & $64.157,97$ & $81.118,33$ & $72.878,6$ \\
\hline
\end{tabular}

A tabela 13 apresenta o cálculo do VPL e do Payback:

Tabela 13 - VPL e Payback

\begin{tabular}{cccccc}
\hline \multicolumn{5}{c}{ Aquisição dos equipamentos à vista } \\
\hline Ano Investimento & Retorno & Saldo & $\begin{array}{c}\text { Retorno } \\
\text { Descontado }\end{array}$ & $\begin{array}{c}\text { Saldo } \\
\text { Descontado }\end{array}$ \\
\hline 0 & $-\mathrm{R} \$ 577.000$ & \multicolumn{5}{c}{$-\mathrm{R} \$ 577.000$} & - $\$ 577.000$ \\
1 & $\mathrm{R} \$ 139.854$ & $-\mathrm{R} \$ 437.146$ & $\mathrm{R} \$ 124.870$ & $-\mathrm{R} \$ 452.130$ \\
2 & $\mathrm{R} \$ 195.239$ & $-\mathrm{R} \$ 241.907$ & $\mathrm{R} \$ 155.643$ & $-\mathrm{R} \$ 296.487$ \\
3 & $\mathrm{R} \$ 167.239$ & $-\mathrm{R} \$ 74.668$ & $\mathrm{R} \$ 119.037$ & $\mathrm{R} \$ 177.450$ \\
4 & $\mathrm{R} \$ 179.839$ & $\mathrm{R} \$ 105.171$ & $\mathrm{R} \$ 114.291$ & $-\mathrm{R} \$ 63.159$ \\
5 & $\mathrm{R} \$ 167.239$ & $\mathrm{R} \$ 272.410$ & $\mathrm{R} \$ 94.896$ & $\mathrm{R} \$ 31.737$ \\
\hline \multicolumn{5}{c}{ Total: } & $\mathbf{R} \mathbf{6 0 8 . 7 3 7 , 0 0}$ \\
\hline \multicolumn{5}{c}{}
\end{tabular}

\begin{tabular}{|c|c|c|c|c|}
\hline \multicolumn{5}{|c|}{ Aquisição dos equipamentos a prazo } \\
\hline Ano Investimento & Retorno & Saldo & $\begin{array}{l}\text { Retorno } \\
\text { Descontado }\end{array}$ & $\begin{array}{c}\text { Saldo } \\
\text { Descontado }\end{array}$ \\
\hline $0-\mathrm{R} \$ 127.000$ & & $-\mathrm{R} \$ 127.000$ & & $-\mathrm{R} \$ 127.000$ \\
\hline 1 & $\mathrm{R} \$ 28.052$ & $-R \$ 98.948$ & $\mathrm{R} \$ 25.047$ & $-\mathrm{R} \$ 101.953$ \\
\hline 2 & $\mathrm{R} \$ 87.798$ & $-\mathrm{R} \$ 11.150$ & $\mathrm{R} \$ 69.992$ & $-R \$ 31.962$ \\
\hline 3 & $\mathrm{R} \$ 64.158$ & $\mathrm{R} \$ 53.008$ & $\mathrm{R} \$ 45.666$ & $\mathrm{R} \$ 13.705$ \\
\hline 4 & $\mathrm{R} \$ 81.118$ & $\mathrm{R} \$ 134.126$ & $\mathrm{R} \$ 51.552$ & $\mathrm{R} \$ 65.257$ \\
\hline 5 & $\mathrm{R} \$ 72.879$ & $\mathrm{R} \$ 207.005$ & $\mathrm{R} \$ 41.353$ & $\mathrm{R} \$ 106.610$ \\
\hline
\end{tabular}


Observando as tabelas observa-se que em caso de compra a vista dos equipamentos utilizando o fluxo econômico a soma dos retornos descontados é de $\mathrm{R} \$$ 608.737,00, subtraindo deste valor o investimento que é de R \$ 577.000,00, obtém-se um Valor Presente Líquido de R\$31.737,00. Já se os equipamentos forem adquiridos a prazo o Valor Presente Líquido é de R\$106.610,00. O payback descontado se os equipamentos forem adquiridos a vista é de 4 anos e 8 meses e se forem comprados a prazo é de 2 anos 8 meses e 12 dias. O cálculo da TIR via planilha eletrônica é de 14,2\% para aquisição a vista e de 38,3\% para aquisição a prazo.

\subsubsection{Resolução da questão (f):}

Levando em consideração o critério do VPL, segundo o qual projetos que tenham VPL maior que zero devem ser aceitos, o projeto em análise mostrou-se ser viável tanto para aquisição à vista quanto a prazo. Quanto ao critério da TIR, devem ser aceitos projetos que tenham TIR superior à Taxa Mínima de Atratividade (TMA) devendo o projeto ser aceito, pois nas duas situações a TIR é maior que a TMA. Em relação ao payback descontado, não está expresso no caso qual o prazo que o empreendedor considera ideal para recuperar o seu investimento. Considerando que a vida útil dos equipamentos e a duração do empréstimo é de 5 anos, nas duas situações o período de recuperação do investimento é menor que este prazo. Desta forma o projeto é viável tanto à vista quanto adquirindo os equipamentos a prazo. No entanto, a compra a prazo mostrou maior viabilidade por apresentar maior VPL, maior TIR e período de recuperação do investimento menor. Conclui-se que o projeto deve ser levado adiante.

\subsubsection{Resolução da questão (g):}

À medida que se reduz a taxa mínima de atratividade no cálculo, reduz também a taxa de desconto dos fluxos de caixa futuros. Com isso, aumentam os valores do retorno e o valor do VPL e também diminui o prazo de recuperação do investimento.

3.7.8 Resolução da questão (h): 
Baseado nas previsões realizadas o projeto é viável e deve ser levado adiante. Mas se as previsões não se realizarem ou forem inferiores às previstas? Como todo e qualquer negócio que se inicia aconselha-se um estudo mais aprofundado do mercado e da concorrência. Quanto mais informações conseguir a respeito do negócio, maiores as chances de as previsões serem acertadas. Cabe ao empreendedor aprofundar o seu entendimento sobre este novo ramo de negócio em que pretende atuar.

\section{CONSIDERAÇÕES FINAIS}

Este caso abordou a viabilidade econômica de uma empresa de terraplenagem. O caso pode ser ampliado pelo professor, se desejado. Pode-se, por exemplo, incluir na descrição outro equipamento com valor de aquisição, manutenção e taxa de juros diferentes e solicitar que os alunos selecionem a melhor alternativa. Sugere-se também aplicar a metodologia de cenários, fazendo pequenas variações na expectativa de horas trabalhadas para mais e para menos (cenário pessimista e otimista) e solicitar que os alunos calculem o impacto destas variações. No cálculo da TIR utilizou-se a resolução por planilha eletrônica, pode-se utilizar também a técnica da TIR modificada.

O presente caso foi aplicado em duas turmas de Administração Financeira e Orçamentária II como critério de avaliação da disciplina. Durante a aplicação anotou-se as dificuldades de interpretação do caso por parte dos alunos e pequenas mudanças foram realizadas para tornar as informações mais claras. $\mathrm{Na}$ ocasião os alunos solucionaram o caso por meio de planilha eletrônica e utilizaram 3 horas de tempo.

Como limitações do caso se destaca o fato dele não considerar os outros impostos incorridos pela empresa. Para fins didáticos optou-se por considerar apenas o imposto de renda. O custo de capital da empresa não foi calculado, optando-se por arbitrar uma taxa, quando o ideal seria calcular o custo de capital da empresa para as duas situações (com o empréstimo e sem o empréstimo). Para simplificar o caso não se considerou a aquisição de mais um caminhão para realizar o transporte da escavadeira, tendo em vista que o equipamento só é transportado de um local de serviço para outro com caminhão.

A partir da resolução do caso por parte do aluno espera-se que o mesmo consiga transpor o conhecimento da teoria para a prática, conseguindo entender através de um exemplo prático a importância e utilidade dos conceitos abordados em sala de aula. Espera-se 
também que o aluno seja capaz de alinhar os conceitos de orçamento com os de viabilidade econômica. 


\section{REFERÊNCIAS}

ASSAF NETO, Alexandre. Matemática financeira e suas aplicações. 10 ed. 3. reimpr. São Paulo: Atlas, 2009.

BRIGHAM, Eugene F.; GAPENSKI, Louis C.; EHRHARDT, Michael C.. Administração Financeira teoria e prática. 1 ed. São Paulo: Atlas, 2001.

GALESNE, Alain; FENSTERSEIFER, Jaime E.; LAMB, Roberto. Decisões de investimento na empresa. 1 ed, São Paulo: Atlas, 1999.

GITMAN, Laurence J. . Princípios de Administração Financeira - Essencial. 2 ed. 2. reimpr. Porto Alegre: Bookman, 2002.

LAPPONI, Juan Carlo. Projetos de investimento: construção e avaliação do fluxo de caixa: modelos em Excel. São Paulo: Lapponi Treinamento e Editora, 2000.

KASSAI, Roberto; KASSAI, Sílvia; SANTOS, Ariovaldo dos; ASSAF NETO, Alexandre. Retorno de investimento - Abordagem Matemática e Contábil do Lucro Empresarial. 2 ed. São Paulo: Atlas, 2000.

SAMANEZ, Carlos Patrício. Matemática Financeira: aplicações à análise de investimentos. 4 ed. 5. reimpr. São Paulo: Pearson Printice Hall, 2009.

SEBRAE. Pesquisa GEM 2013. Disponível em: <http://www.sebrae.com.br/ customizado/estudos-e-pesquisas/temas-estrategicos/empreendedorismo>. Acesso em: $30 \mathrm{de}$ março de 2014.

SOUZA, Alceu; CLEMENTE, Ademir. Decisões financeiras e análise de investimentos. 6 ed. 2 .reimpr. São Paulo: Atlas, 2009.

\section{BIBLIOGRAFIA RECOMENDADA}

ASSAF NETO, Alexandre. Finanças Corporativas e Valor. São Paulo: Atlas, 2012

GITMAN, Lawrence J. Princípios de administração financeira. São Paulo: Pearson Education, 2010.

HOJI, Masakasu. Administração financeira e orçamento: matemática financeira aplicada, estratégias financeiras, orçamento empresarial. 7. ed. São Paulo: Atlas, 2008.

LEMES JUNIOR, Antônio Barbosa; RIGO, Cláudio Miessa; CHEROBIM, Ana Paula Mussi. Administração financeira: princípios, fundamentos e práticas brasileiras. 2. ed. Rio de Janeiro: Elsevier, 2005.

ROSS, Stephen; WESTERFIELD, Randolph; JORDAN, Bradford D. Administração financeira. 2. ed. São Paulo: Atlas, 2010. 